\title{
A Dedication to Trevor Alleyn Thorpe
}

\section{David Songstad ${ }^{1}$}

Published online: 23 November 2020

(C) The Society for In Vitro Biology 2020

This issue of In Vitro Cellular and Developmental Biology - Plant is dedicated to Dr. Trevor Alleyne Thorpe, who passed away on May 18, 2020. Trevor Thorpe had a long and distinguished career, which will be described in the first manuscript in this issue titled "Trevor Alleyne Thorpe: His Academic Life and Scientific Legacy.” More importantly, this manuscript describes the man that became a friend to so many and highlights the positive impact he had on so many lives. What an honor and privilege for those that worked in and collaborated with Trevor's lab, which includes Prakash Kumar, Stephen Chandler, Indra Harry, Chin-yi Lu, Claudio Stasolla, and Edward Yeung, to collect their memories of him for this tribute. It was in 1981 when I first learned of Trevor Thorpe by purchasing his book "Plant Tissue Culture: Methods and Applications in Agriculture" and this book will always have a special place on my book shelf. I also feel privileged to follow in Trevor's footsteps because he was the first Editor-in-Chief of this journal when the society decided to begin publishing what is affectionately known as "In Vitro-Plant". We are all better scientists because of Trevor Thorpe. We are all standing on his shoulders. We now have the commission to carry on his science legacy. Finally, in dedication to Trevor, I am also pleased to announce that Springer has agreed to make this tribute article free to access for the first two months of it appearing online.

Respectfully,

David Songstad, PhD,

Editor-in-Chief

In Vitro Cellular and Developmental Biology - Plant

David Songstad

davidsongstad@aol.com

1 Songstad Consulting, San Marcos, CA, USA 